\title{
Museu ou centro de ciência: flutuações (auto)denominativas nos enunciados do Catavento Cultural e Educacional
}

\author{
Arlete Machado Fernandes Higashi \\ Universidade de São Paulo (USP), São Paulo, São Paulo, Brasil \\ arlete_higashi@hotmail.com
}

DOI: http://dx.doi.org/10.21165/el.v46i3.1594

\begin{abstract}
Resumo
O presente artigo tem por objetivo analisar as flutuações (auto)denominativas presentes no gênero contrato de gestão do Catavento Cultural e Educacional, ressaltando as entonações valorativas que permeiam a construção do discurso identitário da instituição. Para tanto, fundamentar-nosemos nos conceitos bakhtinianos de signo ideológico, entonação valorativa, avaliação social e destinatário e nos estudos de pesquisadores que refletiram sobre os museus e os centros de ciência. Os resultados apontam que essas flutuações são decorrentes de uma constante tensão entre afirmar e negar um perfil museal.

Palavras-chave: Museu de ciência; centro de ciência; Catavento Cultural e Educacional; Círculo de Bakhtin.

\section{Museo o centro de ciencia: fluctuaciones (auto)denominativas en los enunciados del Catavento Cultural y Educacional}

\section{Resumen}

Este trabajo tiene por objetivo analizar las fluctuaciones (auto)denominativas presentes en el género contrato de gestión del Catavento Cultural y Educacional, destacando las entonaciones valorativas que atraviesan la construcción del discurso identificatorio de la institución. Para eso, nos basaremos en los conceptos bakhtinianos de signo ideológico, entonación valorativa, evaluación social y destinatario y en los estudios de investigadores que reflexionaron sobre los museos y los centros de ciencia. Los resultados señalan que esas fluctuaciones revelan una constante tensión entre afirmar y negar un perfil museístico.

Palabras-clave: Museo de ciencia; centro de ciencia; Catavento Cultural y Educacional; Círculo de Bakhtin.

\section{Introdução}

Fundamentado nas noções de signo ideológico, entonação valorativa, avaliação social e destinatário, da teoria dialógica do Círculo de Bakhtin, e nas reflexões de estudiosos da área museal, este artigo visa a analisar a variabilidade (auto)denominativa do Catavento Cultural presente no gênero contrato de gestão ${ }^{1}$, colocando em relevo as entonações expressivas que se materializam no discurso usado para construir a natureza identitária da instituição. Denominações como Museu Catavento, Museu da Criança, Espaço Interativo de Ciência, Espaço Cultural de Ciência figuram de modo intercambiável no decorrer do referido documento, adquirindo um peso específico de

\footnotetext{
${ }^{1}$ De modo geral, o contrato de gestão é um gênero do discurso que requer uma forma padronizada, o que se mostra desfavorável para refletir a expressividade individual do falante. Contudo, no documento analisado, observamos matizes de expressão avaliativa.
} 
expressividade valorativa que gera certa instabilidade interpretativa quanto a considerar o Catavento Cultural como um centro ou um museu de ciência. Tendo em vista que a utilização das palavras na comunicação discursiva é, conforme assinala Bakhtin (2003), de índole individual e contextual, consideramos, num primeiro momento, fundamental observar os aspectos sócio-históricos e ideológicos que influenciaram (e ainda influenciam) as tentativas de definição de museu e centro de ciência, uma vez que, na perspectiva do Círculo de Bakhtin, todo signo ideológico vê-se marcado pelo horizonte social de uma época e de um grupo social determinados. É nesse sentido que Medviédev (2012) postula que compreender um enunciado não significa capturar seu sentido em estado de dicionário, mas entendê-lo na realidade histórica e no contexto da contemporaneidade. Em seguida, à luz das reflexões apresentadas, analisaremos as flutuações identitárias do Catavento Cultural que permeiam o gênero contrato de gestão, comparando-o com o folder de apresentação da instituição, a fachada do Catavento Cultural e a entrevista do professor Osvaldo Guimarães, à época diretor educacional do Catavento, concedida à pesquisadora Adriana de Lima Barbosa.

\section{Museu de ciência versus centro de ciência}

Ao buscar o contexto sócio-histórico do surgimento do museu, encontramos seu primeiro registro a partir do século XV, período em que a palavra museu passou a ser, segundo Valente (2003), associada à ideia de formação de coleções. De acordo com a pesquisadora, a ampliação do colecionismo resultou na criação de outros espaços, como bibliotecas e gabinetes que passaram a ter a função de preservar objetos, manuscritos e vestígios da antiguidade, curiosidades exóticas e naturais, obras de arte e instrumentos científicos, os quais eram expostos também para fins de ensino. Esses ambientes eram utilizados e consolidados com o apoio da nobreza, a qual fomentava o gosto e o interesse pelo saber científico e artístico "que foi propagado pelos que se encontravam no topo da hierarquia social” (VALENTE, 2003, p. 26). Isto nos mostra que esses lugares eram destinados a um público restrito, excluindo, portanto, a maior parte da população. Contudo, de acordo com Valente (2003), os estratos médios da sociedade, compostos por sábios, escritores e artistas eruditos, pressionaram a classe dominante a expandir o acesso às coleções, tendo em vista estudá-las.

Dessa forma, ainda que as exposições não fossem direcionadas a todo tipo de visitante, esses movimentos iniciaram e favoreceram a concepção de museu enquanto instituição de natureza educativa e aberta ao público, a qual, segundo a autora, delineou o perfil museal que permanece ainda agora. Todavia, essa abertura só incluiu a população no final do século XVIII, época em que se difundiu a importância do uso do objeto na aprendizagem (VALENTE, 2003). A partir disso, muitas instituições foram criadas e a definição de museu passou a ser ponto de constantes discussões. Nesse sentido, é possível encontrar interpretações baseadas em diferentes abordagens, como a conceitual, a teórica e a prática (DESVALLÉES; MAIRESSE, 2013). Entretanto, a sua definição mais corrente é, segundo Desvallées e Mairesse (2013), proposta pelo Comitê Internacional dos Museus $^{2}$ (ICOM), o qual o considera como uma instituição permanente, aberta ao

\footnotetext{
2 “Criado em 1946, o ICOM é uma Organização não-governamental que mantém relações formais com a UNESCO. É uma associação profissional sem fins lucrativos, financiada predominantemente pela contribuição de seus membros, por atividades que desenvolve e pelo patrocínio de organizações públicas e privadas". Disponível em: <http://www.icom.org.br/?page_id=4>. Acesso em: 18 dez. 2015.
} 
público com fins de estudo, educação e deleite, que opera sem motivações lucrativas e a serviço da sociedade, adquirindo, conservando, estudando, expondo e transmitindo o patrimônio material e imaterial produzido pelo homem.

É importante mencionar também o posicionamento do Departamento de Museus e Centros Culturais do Instituto do Patrimônio Histórico e Artístico Nacional ${ }^{3}$ que considera o museu enquanto

[...] uma instituição com personalidade jurídica própria ou vinculada a outra instituição com personalidade jurídica, aberta ao público, a serviço da sociedade e de seu desenvolvimento e que apresenta as seguintes características: I - o trabalho permanente com o patrimônio cultural, em suas diversas manifestações; II - a presença de acervos e exposições colocados a serviço da sociedade com o objetivo de propiciar a ampliação do campo de possibilidades de construção identitária, a percepção crítica da realidade, a produção de conhecimentos e oportunidades de lazer; a utilização do patrimônio cultural como recurso educacional, turístico e de inclusão social; IV - a vocação para a comunicação, a exposição, a documentação, a investigação, a interpretação e a preservação de bens culturais em suas diversas manifestações; $\mathrm{V}$ - a democratização do acesso, uso e produção de bens culturais para a promoção da dignidade da pessoa humana; VI - a constituição de espaços democráticos e diversificados de relação e mediação cultural, sejam eles físicos ou virtuais. Sendo assim, são considerados museus, independentemente de sua denominação, as instituições ou processos museológicos que apresentem as características acima indicadas e cumpram as funções museológicas (DEPARTAMENTO DE MUSEUS E CENTROS CULTURAIS IPHAN/MINC, 2005, p. 2).

Como se pode notar, a conceituação postulada pelo departamento acima mencionado propõe elementos e características que parecem contemplar a multiplicidade e as transformações dos eventos sociais, uma vez que permite a inclusão de entidades que, à luz da concepção anterior, poderiam ficar excluídas, como o cibermuseu ${ }^{4}$ e $o$ ecomuseu $^{5}$, que são considerados novas modalidades museais, e até mesmo os centros de ciência, que, para alguns estudiosos, não se enquadram na definição de museu. Isto é um indício de que os sentidos atribuídos a esta noção parecem sofrer as influências não apenas do contexto sócio-histórico passado, mas também do contexto sócio-histórico e ideológico atual. Conforme destacou Medviédev (2012, p. 50), "não importa o que a palavra signifique, [...] ela é sempre parte objetiva e presente do meio social do homem".

Dito de outro modo, os sentidos atribuídos ao museu estabelecem uma ligação com uma dada realidade e, por conseguinte, com as avaliações sociais. Para Medviédev (2012), a avaliação social é a atualização histórica que reúne a presença singular de um

\footnotetext{
${ }^{3}$ Disponível em: <portal.iphan.gov.br/files/questionario_cadastro_nacional_de_museus.doc $>$. Acesso em: 13 dez. 2015

${ }^{4}$ De acordo com Desvallées e Mairesse (2013), cibermuseu caracteriza-se por apresentar “uma coleção de objetos digitalizados, articulada logicamente e composta por diversos suportes que, por sua conectividade e seu caráter multiacessível, permite transcender os modos tradicionais de comunicação e de interação com o visitante [...]; ele não dispõe de um lugar ou espaço real, e seus objetos, assim como as informações associadas, podem ser difundidos aos quatro cantos do mundo" (SCHWEIBENZ apud DESVALLÉES; MAIRESSE, 2004, p. 67).

${ }^{5} \mathrm{O}$ "ecomuseu na sua concepção inicial como uma instituição museal que associa ao desenvolvimento de uma comunidade a conservação, a apresentação e a explicação de um patrimônio natural e cultural pertencente a esta mesma comunidade, representativo de um modo de vida e de trabalho, sobre um dado território, bem como a pesquisa que lhe é associada" (DESVALLÉES; MAIRESSE, 2004, p. 66).
} 
enunciado com a abrangência do seu sentido, o que pode justificar o caráter plástico que a noção de museu vem adquirindo. Nesse sentido, pode-se dizer que o seu significado é também condicionado à entonação valorativa dada pelo meio social e às transformações que ocorrem na realidade histórica como um todo, o que talvez possa explicar a discussão em torno da distinção (ou não) entre um centro e um museu de ciência, pois "é avaliação social que atualiza o enunciado tanto no sentido da sua presença factual quanto no do seu significado" (MEDVIÉDEV, 2012, p. 184). Dessa forma, muitos pesquisadores vêm se debruçando também sobre essa questão, no sentido de destacar as especificidades de cada uma dessas modalidades.

A distinção entre um centro e um museu de ciência tem sido foco de reflexão de diferentes órgãos e estudiosos. O ICOM e o DEMU/IPHAN, por exemplo, parecem inseri-los no mesmo conjunto de museu. Já pesquisadores, como Sabbatini (2004), estabelecem uma diferença entre uma e outra categoria.

Algumas especificidades presentes no gênero museu de ciência podem ser melhor compreendidas se observados seus principais pontos históricos. Encontramos o registro de que o Conservatoire National des Arts et Métiers, instituído em Paris em 1794, pode ser considerado o precursor desse segmento. De acordo com Tibúrcio (2013), o Conservatoire foi concebido para atender a política industrial que visava prover a França de recursos técnicos e pedagógicos para concorrer com os demais países europeus.

Com esse propósito, o acervo da instituição era composto por ferramentas e máquinas que favoreciam a formação de trabalhadores, "logo, a função educativa baseada na demonstração pode ser considerada uma das características do Conservatoire e das instituições que seguiram essa vertente" (TIBÚRCIO, 2013, p. 10-11).

De acordo com Valente (2003), o surgimento das instituições que se seguiram foi condicionado ou pela "força da ciência no seu aspecto da razão" ou pelo nacionalismo, "quando os interesses são capitaneados pelos governos" e, somando-se a isso, pela importância da ciência como parte da cultura e como representante de um dado contexto histórico. Um bom exemplo é a criação do Deutsches Museum em Munique/Alemanha, fundado por Oskar Von Miller em 1903, o qual era visto como um instrumento de prestígio social e de divulgação do progresso trazido pela técnica. Segundo a pesquisadora, essa categoria de museu indicava que a ciência e a tecnologia favoreciam o avanço da sociedade.

Deste modo, esses espaços organizavam suas exposições com modelos reduzidos, os quais representavam as realizações técnico-científicas de um período e do país onde se encontravam, tendo a função de comunicar as invenções, os saberes, os processos industriais e de contribuir para a construção de uma identidade nacional (VALENTE, 2003). É nesse contexto de fomento à ciência e à tecnologia que, na visão de Tibúrcio (2013), os projetos expositivos privilegiaram o uso de objetos para explicar os princípios científicos e industriais, os quais poderiam ser manipulados pelos visitantes.

As exposições presentes nesses ambientes eram centradas na temática científica, sendo criadas para ser um meio de popularização da ciência. Como destaca Valente (2003), nesses lugares estimulava-se a participação do visitante por meio da experimentação de modelos direcionada por mediadores treinados para a função.

Assim, tendo em vista atingir diferentes tipos de público, os museus de ciência passaram por transformações determinantes para a criação de novos espaços expositivos. 
Historicamente, na visão de Silva et al. (2002), os anos 1970, 1980 e 1990 marcaram as grandes alterações expositivas, seja no aspecto museográfico, seja nos procedimentos pedagógicos e comunicacionais.

No final dos anos 1980, por exemplo, o Ministério da Educação Nacional da França promoveu, segundo os pesquisadores, diversas reflexões a respeito dos museus de ciência e suas exposições. O produto dessas reflexões foi a criação do documento Definition et role d'un Musée de l'Éducation Nationale, o qual estabelece diretrizes a serem aplicadas na concepção e montagem das exposições dos museus de ciência, como enfatizar a experimentação, ressaltar o processo histórico de geração de documento e reunir os conhecimentos expostos num todo coerente, por exemplo (HERINTIER-AUGE et al., 1991 apud SILVA et al., 2002).

Desse modo, com vistas a se ajustarem a um novo perfil e aos padrões mencionados acima, as exposições aderiram a temáticas mais diversificadas e a instalações mais inovadoras. Nesse sentido, pode-se afirmar que as constantes transformações na expografia científica foram, e ainda são, sujeitas às coerções da própria esfera de atuação (a cultural), bem como são condicionadas às influências de outros campos da vida social, como o político, o educacional, o científico e o cotidiano (no sentido de ajustar o discurso expositivo ao nível de conhecimento e às reações do visitante-destinatário presumido), as quais atuam em diferentes modos e momentos da idealização, produção e instalação das exposições. Acreditamos que tudo isso impulsione não apenas uma nova configuração às entidades já existentes, mas também a criação de novos espaços dedicados à divulgação científica, como os centros de ciência, por exemplo.

De acordo com Silva et al. (2002), o centro de ciência afasta-se da ideia de museu de ciência por apresentar exposições interativas ${ }^{6}$. No entanto, mostramos que os primeiros museus de ciência e técnica já apresentavam o conhecimento por meio de modelos que podiam ser manipulados pelos visitantes. Ou seja, o aspecto interacional entre a exposição e o visitante, que geralmente é atribuído como uma das especificidades do centro de ciência, não foi uma estratégia inovadora. Entretanto, para alguns estudiosos, a interatividade (manipulativa) é justamente um dos limites tênues que pode diferenciá-los.

Cazelli (1992) é uma das especialistas que ressalta a existência de museus que se dedicam a expor a história da ciência, apresentando aos visitantes os equipamentos científicos do passado, o que se contrapõe à concepção de centro de ciência, "que provoca, atrai, seduz e motiva o visitante a entrar em contato com alguns fundamentos da CeT por meio de experimentos do tipo "faça você mesmo"' (CAZELLI, 1992, p. 18), cuja proposta é, na visão da autora, a educação para ciência.

A distinção entre um centro e um museu de ciência também foi foco de reflexão na pesquisa de Sabbatini (2004). O pesquisador ratifica a concepção de centro de ciência enquanto espaço destinado às exposições interativas, cuja função é demostrar um princípio científico e tecnológico, ressaltando os aspectos práticos sobre os teóricos. Nesses espaços, o visitante é, na visão do autor, estimulado a explorar o artefato e a descobrir o princípio por si mesmo. Já os museus de ciência particularizam-se por exibirem coleções de artefatos, ferramentas e aparatos científicos em benefício da

\footnotetext{
${ }^{6}$ Comumente, no campo museal, o conceito de interatividade está relacionado com o manuseio do acervo por parte do visitante-destinatário.
} 
posteridade e da missão conservacionista, o que pareceria estar ausente nos centros de ciência.

Alguns estudiosos não estabelecem uma distinção nítida entre esses dois segmentos. Gaspar (1993), por exemplo, os enquadra como instituições de educação informal, o que não se confunde com a educação formal e a não-formal, na medida em que a primeira não se submete aos "currículos tradicionais, não oferece graus ou diplomas, não tem caráter obrigatório de qualquer natureza e não se destina exclusivamente aos estudantes, mas também ao público em geral" (GASPAR, 1993, p. 34), a segunda é subordinada a uma grade curricular e a terceira caracteriza-se pela flexibilidade metodológica/curricular. Para a autora, a função principal dessas instituições é a alfabetização em ciências.

Corroborando esta ideia, Tundisi (1998) observa que os centros de ciência têm a função de contribuir à qualidade de ensino de primeiro e segundo graus, ao aperfeiçoamento de professores/alunos e ao desenvolvimento de estratégias de interação com a população em geral.

A delimitação do museu ou do centro de ciência como instituições de educação, seja formal, não formal ou informal mostra-se, a princípio, simplificada, no sentido de que a complexidade desses conceitos talvez não pontue as características e os objetivos dessas entidades. Além disso, consideramos que os museus e os centros de ciência, mais precisamente suas exposições, são iniciativas de divulgação científica que apresentam finalidades que podem ultrapassar aquelas mencionadas pelos pesquisadores citados acima. A nosso ver, a exposição de ciência é uma das formas de comunicação ideológica que, como bem notou Medviédev (2012), mostra-se extremamente complexa, quer seja veiculada num museu ou num centro de ciência. "Cada ato de reflexão cognitiva é determinado pela orientação mútua entre as pessoas, e quanto mais complexa, diferenciada e organizada for essa orientação, tanto mais essencial e profundo será o conhecimento" (MEDVIÉDEV, 2012, p. 56).

Dessa maneira, convergimos com Vogt (2006) que propõe não confundir a comunicação das ciências e das tecnologias com o ensino, visto que no processo comunicativo "temos a liberdade de participar ou não, cuja mensagem continuamos livres para entender bem ou mal, ou para entendê-la em parte, ou entendê-la ao contrário, ou não entendê-la absolutamente" (VOGT, 2006, p. 22). Para este autor, a inclinação em reduzir o tema da comunicação da ciência a simples transmissão de conhecimento, geralmente, afasta o objetivo principal dessa atividade: aproximar, compartilhar e estimular. Assim, nesta perspectiva, o desenvolvimento científico é, para Vogt, um processo cultural, "quer seja ele considerado do ponto de vista de sua produção, de sua difusão entre os pares ou na dinâmica social do ensino e da educação, ou ainda, do ponto de vista de sua divulgação na sociedade [...]" (VOGT, 2006, p. 24).

Em sentido amplo, é possível pensar que os centros e museus de ciência são produtos ideológicos "refletores e refratores da existência", que, inseridos na esfera cultural, estabelecem, por meio das exposições, relações dialógicas com diferentes esferas ideológicas, incluindo-se aí a educacional. Assim, estas relações

[...] colocam em contato diferentes esferas de produção de saberes, compostos por centros valorativos próprios, por seus gêneros, por suas imagens, por seus cronotopos. Esse contato permite não só o aumento do estado de conhecimento do destinatário presumido, 
como submete os saberes científicos e tecnológicos a uma avaliação crítica viva (GRILLO, 2013, p. 89).

O aumento do estado de conhecimento na sociedade integra-se aos objetivos da divulgação científica e, por conseguinte, aos dos centros e museus de ciência. No entanto, esse aumento do estado de conhecimento no destinatário parece não se relacionar diretamente com o ensino de uma área do saber. Antes de tudo, pode-se buscar a criação de uma cultura científica na sociedade, a qual possa atuar tanto na formação de uma opinião pública que se mobiliza em relação aos saberes e às orientações da esfera científica, quanto na formação de uma cultura individual (GRILLO, 2009).

Sintetizando as proposições tratadas até aqui, notamos que é consensual um museu de ciência distinguir-se de um centro de ciência, na medida em que o primeiro é alicerçado na ideia de instituição que expõe e explica, por meio de modelos e aparatos, a herança científica e tecnológica de uma determinada época. Por conseguinte, isso dialoga com a noção mais corrente de museu enquanto instituição voltada para a aquisição, estudo, conservação e exposição permanente do patrimônio material e imaterial da humanidade. Já o segundo, enquanto um dos movimentos relativamente recentes de divulgação científica, renuncia uma visão histórica e preservacionista para focar-se na apresentação das descobertas mais atuais da ciência por meio de um discurso expositivo essencialmente interativo.

A nosso ver, o centro e o museu de ciência, entendidos como produtos ideológicos destinados à divulgação científica, transferem "a realidade conhecida e avaliada para um outro plano axiológico, submete-a a uma nova unidade, ordena-a de modo novo: individualiza-a, concretiza-a, isola-a, arremata-a, mas não recusa a sua identificação nem sua valoração" (BAKHTIN, 2010, p. 33, grifos do autor), dando um novo acabamento e criando uma nova relação axiológica com os elementos que já se tornaram realidade para o conhecimento. Entendemos que essas instituições, e seus respectivos projetos expositivos, são duplamente orientadas: em primeiro lugar para os visitantes-destinatários presumidos e, em segundo lugar, "para a vida, para seus acontecimentos, problemas, e assim por diante" (MEDVIÉDEV, 2012, p. 195). E este duplo direcionamento confere diferentes tipos de acabamento (temático, composicional, estilístico e valorativo) ao discurso de divulgação científica, que são capazes de delimitar, ainda que de forma tênue, suas fronteiras.

Diante das considerações expostas e de nosso papel de observador-pesquisador, procuraremos, na próxima seção, analisar as flutuações (auto)denominativas presentes no gênero contrato de gestão do Catavento Cultural, comparando-o com o folder de apresentação da instituição, a fachada do Catavento Cultural e a entrevista do professor Osvaldo Guimarães ${ }^{7}$, com vistas a delimitar a instituição seja como um museu de ciência, seja como um centro de ciência ${ }^{8}$.

\footnotetext{
${ }^{7} \mathrm{O}$ excerto da entrevista aqui analisado faz parte do trabalho da pesquisadora Adriana Barbosa de Lima, intitulado "Museus e Centros de Ciência: Gestão, Educação e Sociedade (Catavento, Sabina, e Museu exploratório de Ciências)". No referido trabalho, a estudiosa analisa as três propostas das instituições mencionadas, considerando seus aspectos educativos e lúdicos.

${ }^{8}$ É importante mencionar que, nos limites deste trabalho, não é possível analisar outros materiais que também poderiam inscrever a identidade da instituição, como os enunciados verbo-visuais que constituem o site do Catavento, por exemplo.
} 
Catavento cultural e Educacional: museu ou centro de ciência? O Catavento Cultural e Educacional foi fundado em 2009 e ocupa o antigo Palácio das Indústrias, prédio centenário e tombado pelos órgãos de preservação do patrimônio histórico, o qual está situado dentro de um parque com $35 \mathrm{mil} \mathrm{m}^{2}$, sendo 8 mil de área construída. $\mathrm{O}$ acervo é constituído por 250 instalações, incluindo os objetos históricos da Fundação Museu de Tecnologia de São Paulo e do Centro Contemporâneo de Tecnologia (doravante, MUSEUTEC/CCT), as quais estão distribuídas em quatro seções, a saber: Universo, Vida, Engenho e Sociedade. Na seção Universo, o destinatário-visitante conta com exposições que versam a respeito de assuntos relacionados ao espaço sideral e à terra. Já no espaço Vida, pode-se ver a evolução do primeiro ser vivo até o homem. Na seção Engenho, apresentam-se as criações do homem dentro da ciência e, por fim, na Sociedade expõem-se os problemas da convivência organizada humana. Uma vez exposta a constituição do Catavento, passemos à discussão acerca das flutuações denominativas presentes no nosso corpus.

Por meio da leitura analítica do contrato de gestão $97 / 2012$, estabelecido entre o Estado de São Paulo, por intermédio da Secretaria do Estado da Cultura, e a Organização Social ${ }^{10}$ Catavento Cultural e Educacional, observamos que os termos museu, museu da criança, museu Catavento, espaço cultural de ciência, espaço interativo que apresenta a ciência aparecem de modo alternado para especificar a entidade. Isto pode revelar determinadas particularidades, entre elas, a inscrição do destinatário presumido, a entonação valorativa dada ao objeto de discurso e a natureza ideológica do Catavento, visto que a palavra, enquanto um fenômeno ideológico por excelência, é capaz de assumir qualquer função ideológica específica: estética, científica, moral, religiosa (BAKHTIN/VOLOCHÍNOV, 2006).

Vejamos a seguir como isto é refletido na inconstância terminológica presente no documento já referido acima:

\begin{abstract}
O presente Contrato de Gestão tem por objetivo o fomento e a operacionalização da gestão e execução, pela contratada, das atividades e serviços na área cultural no ESPAÇO CULTURAL DA CRIANÇA/MUSEU CATAVENTO em conformidade com o "Anexo 1 - Plano de Trabalho" que integra este instrumento. (CONTRATO DE GESTÃO 7-2012, p. 2, grifos nossos).

Administrar, em parceria com a Secretaria de Estado da Cultura por meio da Unidade de Preservação Museológico, o Catavento - Espaço Cultural de Ciência, garantindo a preservação, a pesquisa e a divulgação de seus acervos culturais materiais e imateriais, e o cumprimento de sua missão institucional, e atuar intensivamente no fortalecimento do Sistema Estadual de Museus - SISEM, em estreita consonância com a política museológica e com as
\end{abstract}

\footnotetext{
9 Apresentando uma forma padronizada, o contrato de gestão tem o objetivo firmar uma parceria entre o Poder Público e administração direta, indireta e entidades privadas, como as organizações sociais, sendo assinado por seus representantes legais. No caso do documento ora analisado, o contratante é o Governo do Estado e a contratada, a Organização Social Catavento Cultural, os quais são representados respectivamente por Marcelo Mattos Araújo e Sebastião Alberto Lima, o que não implica considera-los como autores dos enunciados que constituem o referido contrato. Bakhtin (2003, p. 308) menciona que todo texto tem um autor (o falante ou quem escreve), no entanto, ele também admite que "em certos limites, a análise linguística pode até abstrair inteiramente da autoria". Dessa forma, neste trabalho, atribuímos uma autoria institucional aos enunciados que constituem o documento, o folder e a fachada do Catavento Cultural.

${ }^{10}$ Uma organização social é, segundo Azevedo (s/d), uma denominação, um título, que a Administração concede a uma entidade privada, sem fins lucrativos, para que ela possa receber determinados benefícios do Poder Público (fundos orçamentários, isenções fiscais etc.), para o cumprimento de seus fins, que devem ser essencialmente de interesse da comunidade.
} 
diretrizes do Estado estabelecidas pela UPPM/SEC (CONTRATO DE GESTÃO 7/2012, p. 16, grifos nossos).

Como podemos observar, neste excerto aparecem três especificações diferentes: Espaço Cultural da Criança/Museu Catavento e Catavento-Espaço Cultural de Ciência. Essas denominações parecem não apenas inscrever a natureza da entidade e o destinatário presumido, mas também refletir uma determinada entonação valorativa em relação ao Catavento Cultural como um todo. Assim, temos, como mostra o trecho, um museu, cujo destinatário presumido é, num primeiro momento, a criança e que se assume valorativamente como um espaço cultural de ciência, tendo como funções preservar, pesquisar e divulgar os seus acervos culturais materiais e imateriais, papéis que parecem dialogar com as motivações museais apontadas pelo ICOM.

Outro elemento que merece destaque é a aliança assumida entre a instituição e o Sistema Estadual de Museus, o que sugere e corrobora sua inserção no campo museal. Além disso, essa aliança reforça a ideia de que os centros e os museus de ciência estabelecem relações dialógicas com outras esferas sendo, portanto, atravessados pelos valores nelas incluídos.

À medida que essas (auto)denominações institucionais se intercalam, observamos um movimento que parece ampliar as particularidades apontadas acima:

Criado com a vocação de ser um espaço interativo que apresente a ciência de forma instigante para crianças, jovens e adultos, desde sua inauguração o Museu Catavento tem sido grande fenômeno de público [...] (CONTRATO DE GESTÃO 7/2012, p. 14, grifos nossos).

(3) Ampliar as possiblidades de aproveitamento das exposições por meio da oferta de serviço educativo [...] para grupos de visitantes turistas, idosos, profissionais e outros. Desenvolver e executar projetos que promovam a inclusão social, trazendo ao museu ou levando o museu a grupos sociais diversificados, marginalizados e com maior dificuldade no acesso a equipamentos culturais (tais como pessoas com deficiência, pessoas em situação de vulnerabilidade social) ou que estejam no entorno do museu. (CONTRATO DE GESTÃO 7/2012, p. 21, grifos nossos).

Nesses trechos, apontamos um relativo aumento do auditório social presumido, o qual aparece atrelado apenas às denominações Museu Catavento/Museu. No entanto, estas denominações se aliam, ao mesmo tempo, a uma entonação valorativa que visa construir uma ideia de espaço interativo e instigante que, somada à assunção de espaço cultural, inscreve caraterísticas condizentes com o perfil de centro de ciência já mencionado na seção anterior. Assim, podemos dizer que, embora a entidade reconheça uma determinada natureza museal, essas oscilações e alianças parecem representar o desejo de afastar-se da noção de museu clássico, cuja principal especificidade é a exposição de objetos de natureza histórica que, geralmente, prevê um destinatáriovisitante mais afeito à contemplação. Ou seja, a nosso ver, o que permeia todo documento é uma espécie de tensão entre negar e afirmar um possível vínculo com a noção tradicional de museu.

Talvez, esta tensão, ou vozes em disputa, possa ser explicada por duas razões: a primeira, pela depreciação valorativa que a palavra museu possui no horizonte social, especialmente na esfera do cotidiano, uma vez que, de modo geral, sua significação se reduz à ideia de lugar destinado à exposição e à contemplação passiva de achados antigos. Assim, antecipando e contrapondo essa possível compreensão responsiva de negação pelo 
destinatário-visitante, o próprio nome da instituição - Catavento Cultural -, bem como seu logotipo - o brinquedo cata-vento -, remetem a uma pluralidade de sentidos que pretende atenuar tal compreensão e despertar simpatia e aceitação por parte desses mesmos destinatários presumidos. Desse modo,

Toda palavra usada na fala real possui não apenas tema e significação no sentido objetivo, de conteúdo, desses termos, mas também um acento de valor ou apreciativo, isto é, quando um conteúdo objetivo é expresso (dito ou escrito) pela fala viva, ele é sempre acompanhado por um acento apreciativo determinado (BAKHTIN/VOLOCHÍNOV, 2006, p. 137, grifos do autor).

A segunda razão é a necessidade de se levar em conta a relação estabelecida entre o Catavento e o Sistema Estadual de Museus e, sobretudo, a existência de artefatos históricos na instituição, os quais, conforme mencionado anteriormente, são de propriedade da MUSEUTEC/CCT. Assinalamos ainda que o acervo da MUSEUTC/CCT tem uma ênfase na difusão do patrimônio histórico-tecnológico, sendo, segundo o Estatuto Social da fundação, direcionado, essencialmente, para o público jovem, cujas principais finalidades transcrevemos no excerto abaixo:
I - Elevação do nível cultural, educacional e tecnológico da sociedade pela compreensão do caminho da tecnologia e sua mutação; pelo desenvolvimento das faculdades críticas e do espírito de pesquisa, alargando horizontes e estimulando a criatividade e a atividade inventiva, principalmente dos jovens; pela democratização do conhecimento e do contato da população com as conquistas tecnológicas da humanidade e com o mundo da tecnologia; II - preservação e difusão do patrimônio tecnológico, histórico e cultural representado pelo acervo; III - motivação e interesse da população pela preservação da memória tecnológica do País; IV - instituição de um espaço cultural novo e diferenciado à serviço da população (ESTATUTO DA FUNDAÇÃO MUSEU DA TECNOLOGIA DE SÃO PAULO, 2010, p. 1, grifos nossos).

Os elementos por nós grifados mostram que a divulgação científica em nenhum momento é mencionada no trecho. Entretanto, nos documentos do Catavento, identificamos uma ênfase nos saberes de diferentes áreas do conhecimento científico, indicando que

A cada etapa do desenvolvimento da sociedade, encontram-se grupos de objetos particulares e limitados que se tornam objeto da atenção do corpo social e que, por causa disso, tomam um valor particular. Só este grupo de objetos dará origem a signos, tornarse-á um elemento da comunicação por signos. (BAKHTIN/VOLOCHÍNOV 2006, p. 46).

De acordo com tal perspectiva, todas as entonações valorativas anseiam ao reconhecimento social e a uma reação ideológica. Nesse sentido é que observamos as oscilações (e associações) denominativas do Catavento Cultural. A nosso ver, ainda que a palavra museu seja recorrente nos documentos oficiais da instituição, denominações como as de espaço cultural de ciência, espaço cultural da criança e espaço interativo que apresenta a ciência de forma instigante marcam as entonações valorativas que atestam o desejo da entidade em ser reconhecida como um espaço dedicado à divulgação do conhecimento científico cuja perspectiva possa dialogar com as especificidades encontradas num centro de ciência. Ao comparar a construção identitária do Catavento presente no contrato de gestão com outros materiais que também poderiam identificar a natureza da instituição, observamos aspectos que parecem ratificar o que acabamos de assinalar. 
A palavra museu, por exemplo, não aparece na fachada principal do Palácio das Indústrias, lugar que abriga as exposições. Nela, o que se destaca é a palavra Catavento, que está localizada entre a ilustração de um cata-vento (logotipo da organização) e o símbolo do Governo do Estado de São Paulo e, abaixo, as fotos de visitantes em interação com as exposições. Em meio a tudo isso, tem-se a inscrição: "divertindo e ensinando ciência e cultura para adultos, jovens e crianças", que dialoga com toda a dimensão visual da fachada:

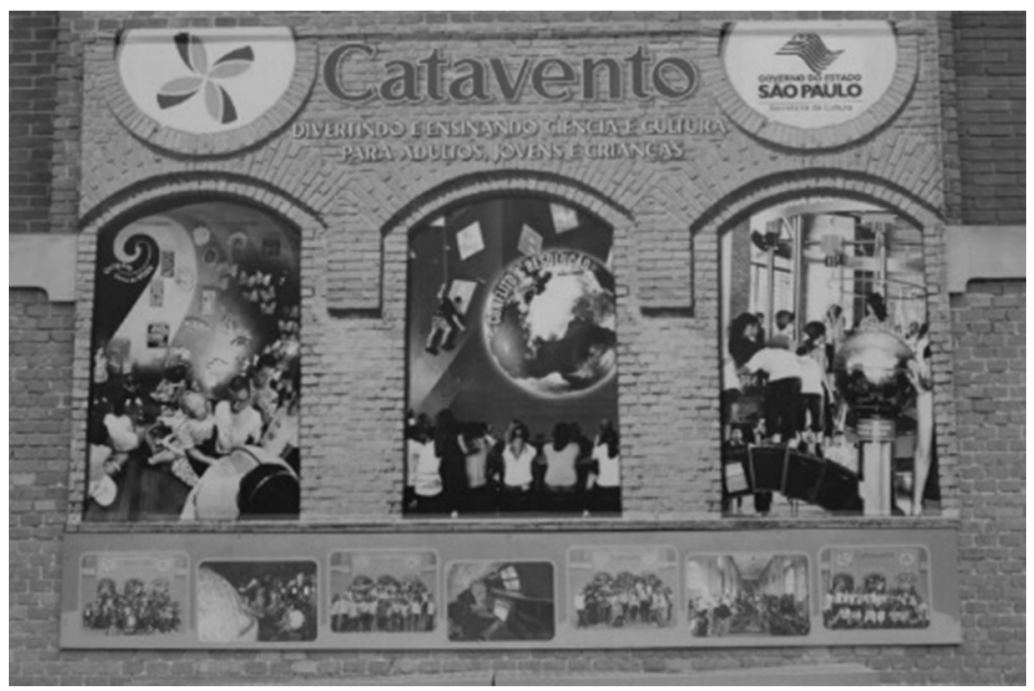

Figura 1. Fachada do Catavento Cultural

Chamamos a atenção para o fato de que, embora o aspecto educacional esteja representado pela palavra "ensinando" e pela imagem sugestiva de estudantes, o que se ressalta na placa-propaganda é a natureza lúdica, interativa e dinâmica que a instituição quer reforçar. Essa natureza é materializada, visualmente, pelo próprio símbolo do brinquedo cata-vento e pelas fotografias de visitantes que manipulam as exposições e, verbalmente, pela palavra "divertindo" que aparece antes de tudo.

Do mesmo modo, no folder de apresentação da instituição, a ideia de museu é substituída pela de espaço cultural e educacional que apresenta ciência e problemas sociais, cujo destinatário-visitante previsto deixa de ser a criança e passa a ser o público em geral e, especificamente, o jovem:

O Catavento cultural é um espaço cultural e educacional que apresenta ao público, especialmente o jovem, a ciência e os problemas sociais, de um modo atraente e participativo [...]. Menores de 7 anos devem ser encaminhados à sala Pequeninos, que funciona somente aos sábados e domingos. Nesta sala encontrarão supervisão habilitada (FOLDER DE APRESENTAÇÃO DA INSTITUIÇÃO CATAVENTO CULTURAL E EDUCACIONAL, grifos nossos).

Assim, pode-se dizer que as especificações Espaço Cultural da Criança e Museu Catavento usadas no contrato de gestão parecem não dialogar com o que é preconizado na fachada e no folder da instituição, visto que nesses não há qualquer menção à ideia de museu, bem como fica explícito no folder que a entidade não prevê visitantes menores de sete anos, ou seja, a denominação Museu da Criança presente no contrato de gestão parece não se justificar. 
Desse modo, o que se espera é provocar, nos termos de Bakhtin/Volochínov (2006), uma "reação semiótico-ideológica", no sentido de que a imagem de centro de ciência, que se quer ressaltar, adquira um valor social

[...] já que o signo se cria entre indivíduos, no meio social; é, portanto, indispensável que o objeto adquira uma significação interindividual; somente então é que ele poderá ocasionar a formação de um signo. Em outras palavras, não pode entrar no domínio da ideologia, tomar forma e aí deitar raízes senão aquilo que adquiriu um valor social. É por isso que todos os índices de valor com características ideológicas, ainda que realizados pela voz dos indivíduos (por exemplo, na palavra) ou, de modo mais geral, por um organismo individual, constituem índices sociais de valor, com pretensões ao consenso social, e apenas em nome deste consenso é que eles se exteriorizam no material ideológico (BAKHTIN/VOLOCHÍNOV, 2006, p. 46, grifos do autor).

Diante de tudo isso, entendemos que, embora o termo museu permeie todo o contrato, a instituição espera aproximar-se do universo dos centros de ciência, cuja característica principal é, como visto na primeira seção, a criação de exposições interativas, dinâmicas e lúdicas, as quais tendem a apresentar as descobertas mais recentes da ciência. Para tanto, recorre, estrategicamente, ao uso de expressões valorativas que se constituem como signos ideológicos que indicam a distinção institucional do Catavento Cultural. Autodenominações como espaço cultural de ciência e espaço interativo que apresenta a ciência favorecem o apagamento de possíveis laços com as práticas museais de caráter mais histórico, como a exposição de artefatos em vitrinas que parece prever um destinatário-contemplador mais passivo, em sentido amplo.

É interessante mencionar que esse apagamento se materializa também na entrevista do professor Osvaldo Guimarães, à época diretor educacional do Catavento, concedida à pesquisadora Adriana de Lima Barbosa:

(6) [Osvaldo] O Catavento foi criado - inaugurado em março de 2009, com essa intenção que fosse um centro de ciência não só exatas e biológicas, mas também humanas [...].

[Adriana] Vocês se entendem como Museu de Ciência e Tecnologia?

[Osvaldo] Não nos entendemos. Não é nada velho aqui, não são museus, pois tudo é novo, todas foram elaboradas para transmitir alguma mensagem ou sair com um ponto de exclamação ou de interrogação daqui, ou vários. Embora a gente tenha uma parceria com o Museu de Tecnologia, são museológicas, mas robustas [...] (BARBOSA, 2014, p. 3-5, anexo 2, grifos nossos).

Como se vê, o discurso individual do diretor educativo também é atravessado por posicionamentos valorativos. Aqui, mais uma vez, as particularidades da palavra museu, enquanto signo ideológico representativo de lugar destinado à exposição de coisas velhas, são enfaticamente rechaçadas: "não nos entendemos, não é nada velho aqui, não são museus, pois tudo é novo". Não é difícil notar a entonação expressiva presente no enunciado do então diretor, comprovando que, como bem destacou Bakhtin (2003, p. 291), "quando escolhemos as palavras para o enunciado é como se nos guiássemos pelo tom emocional próprio de uma palavra isolada: selecionamos aquelas que pelo tom correspondem à expressão do nosso enunciado e rejeitamos as outras". Para o autor russo, a entonação valorativa é um dos recursos para expressar a relação volitivo-emocional do locutor com o objeto do seu discurso. 
De acordo com Barbosa (2014), Osvaldo Guimarães afirma que o perfil do Catavento se equipara à do Exploratorium, nos Estados Unidos; ao Cosmocaixa, na Espanha; ao Pæno, na Alemanha; ao Technorama, na Suíça; ao Museu de Ciência e tecnologia da PUC, no Rio Grande do Sul, e, numa escala menor, à fundação Oswaldo Cruz, no Rio de Janeiro, os quais são referências de centros de ciência. Essa comparação reforça a ideia de que,

Em cada época, em cada círculo social, em cada micromundo familiar, de amigos e conhecidos, de colegas, em que o homem cresce e vive, sempre existem enunciados investidos de autoridade que dão o tom, como as obras de arte, ciência, jornalismo político, nas quais as pessoas se baseiam, as quais elas citam, imitam, seguem. Em cada época e em todos os campos da vida e da atividade, existem determinadas tradições expressas e conservadas em vestes verbalizadas: em obras, enunciados, sentenças, etc. Sempre existem essas ou aquelas ideias determinantes "dos senhores do pensamento" de uma época verbalmente expressa, algumas tarefas fundamentais, lemas, etc. (BAKHTIN, 2003, p. 294).

Ao equiparar o Catavento Cultural a estas instituições, o diretor visa criar princípios específicos que o separam do campo museal. Para tanto, desenvolve seu discurso individual em uma interação constante com as criações expositivas bemsucedidas no Brasil e em outros países. Em uma visão bakhtiniana, podemos dizer que o discurso produzido se orienta para o "já-dito", para o "já-conhecido". Vale mencionar que, no mesmo trecho, o diretor reconhece a existência do acervo histórico da MUSEUTEC/CCT, contudo, tenta apagar os significados negativos que julga serem constitutivos da palavra museu/museológico, recorrendo, para tanto, à escolha da conjunção adversativa mas, para acentuar a oposição a esses significados, e do adjetivo robustas, para delimitar a sua entonação valorativa em relação ao seu objeto de discurso: o Catavento. Para usar as palavras de Bakhtin (2003, p. 294), "neste caso, a palavra atua como expressão de certa posição valorativa do homem individual (de alguém dotado de autoridade: do escritor, cientista, pai, mãe, amigo, mestre, etc.) como abreviatura do enunciado". Assim, o que se ressalta na construção do discurso identitário do Catavento Cultural é a imagem de instituição que possui especificidades condizentes com o que se convencionou chamar de centro de ciência, uma vez que os sentidos que estão associados ao termo centro de ciência tendem a despertar mais simpatia no meio social, visto que "as palavras são tecidas a partir de uma multidão de fios ideológicos e servem de trama a todas as relações sociais em todos os domínios" (BAKHTIN/VOLOCHÍNOV, 2006, p. 42).

Tendo em vista estas considerações, a nosso ver, o Catavento Cultural e Educacional apresenta um discurso identitário de formação híbrida ${ }^{11}$, no sentido bakhtiniano do termo. É interessante notar ainda que, de acordo com nossas observações in loco, a entidade apresenta tanto o perfil de um museu de perspectiva mais histórica quanto o de um centro de ciência. A aproximação com o museu se dá, obviamente, por meio da aquisição, conservação e exposição do acervo histórico da MUSEUTEC, o qual também compõe as instalações do Catavento. No entanto, é importante mencionar que, excetuando os escassos objetos e maquetes em vitrinas, o trabalho conceitual de

${ }^{11}$ Bakhtin (2010, p. 110) denominou "construção híbrida o enunciado que pertence a um único falante, mas onde, na realidade, estão confundidos dois enunciados, dois modos de falar, dois estilos, duas 'linguagens', duas perspectivas semânticas e axiológicas". 
exposição desse acervo não prevê uma participação passiva do visitante, o que dialoga com as proposições de concepção e montagem de exposições de ciências destacadas no documento Definition et role d'un Musée de l'Éducation Nationale mencionadas na seção anterior. Já a aproximação com o centro de ciência materializa-se por meio de um projeto expográfico essencialmente interativo e lúdico, o qual enfatiza os processos e as descobertas científicas mais recentes. Destacamos que esta última aproximação se sobrepõe à primeira, o que pode justificar a defesa do então diretor educacional da instituição em classificá-la como um centro de ciência.

\section{Considerações finais}

O presente trabalho buscou mostrar que a flutuação (auto)denominativa presente no gênero contrato de gestão do Catavento Cultural é resultado de uma constante tensão entre afirmar e negar um perfil museal. Entendemos que os sentidos agregados à palavra museu, que no horizonte social é associada à ideia de exposição de acervos históricos fetichizados, são os que mais contribuem para a inserção de outras denominações. Qualificações como espaço cultural de ciência, espaço cultural da criança, espaço interativo que apresenta a ciência de forma instigante e espaço interativo de ciência adquirem um peso específico, constituindo-se como entonações valorativas que rechaçam possíveis articulações entre o Catavento Cultural e os museus clássicos. Além disso, tais denominações buscam cumprir a função de identificar a individualidade constitutiva das exposições de divulgação científica presentes no Catavento.

Dessa forma, podemos dizer que, como bem observou Bakhtin (2010), em qualquer meio é possível sobrecarregar as palavras com intenções e acentos específicos para torná-las alheias às outras correntes, partidos, obras e pessoas. Para o autor, toda manifestação verbal tem o poder de contagiar com suas intenções os elementos da linguagem que estão integrados na sua origem semântica e expressiva, impondo-lhes nuanças de sentido precisas e tons de valores definidos. Lembramos que o contrato de gestão é um gênero secundário padronizado e, por conseguinte, não muito propício ao reflexo da expressão da individualidade do falante/escrevente. Todavia, vimos que a flutuação denominativa presente no corpus é decorrente de um certo grau de expressividade valorativa materializada nas escolhas linguísticas que visam construir a natureza identitária do Catavento Cultural e Educacional.

\section{REFERÊNCIAS}

AZEVEDO, A. E. Organizações sociais. Disponível em: $<$ http://www.pge.sp.gov.br/centrodeestudos/revistaspge/revista5/5rev6.htm>. Acesso em: 12 out. 2015.

BAKHTIN, M. (VOLOCHÍNOV). Marxismo e filosofia da linguagem. 6. ed. Tradução de Yara Frateschi. São Paulo: Hucitec, 2006 [1929].

BAKHTIN, M. Estética da criação verbal. Tradução de Paulo Bezerra. São Paulo: Martins Fontes, 2003[1952-1953].

Questões de literatura e de estética: a teoria do romance. 6. ed. Tradução de Aurora. Fornoni. Bernadini et al. São Paulo: HUCITEC, 2010 [1924]. 
BARBOSA, L. A. Museus e centros de ciência: gestão, educação e sociedade. 2014. 99 f. Dissertação (Mestrado em Divulgação Científica e Cultural) - Instituto de Estudos da Linguagem, Universidade Estadual de Campinas, Campinas, 2014.

CAZELLI, S. Alfabetização científica e os museus interativos de ciência. Rio de Janeiro, 1992. 163 f. Dissertação (Mestrado em Educação) - Pontifícia Universidade Católica, Rio de Janeiro, 1992.

DEPARTAMENTO DE MUSEUS E CENTROS CULTURAIS IPHAN/MINC. 2005. Disponível em: $<$ http://portal.iphan.gov.br/files/questionario_cadastro_nacional_de_museus.doc $>$. Acesso em: 13 dez. 2015.

DESVALLÉES, A.; MAIRESSE, F. Conceitos-chave de Museologia. Tradução de Bruno Brulon Soares e Marília Xavier Cury. São Paulo: Comitê Brasileiro do Conselho Internacional de Museus: Pinacoteca do Estado de São Paulo: Secretaria de Estado da Cultura, 2013.

ESTATUTO DA FUNDAÇÃO MUSEU DA TECNOLOGIA DE SÃO PAULO, 2010. Disponível em: <http://docplayer.com.br/10771104-Estatuto-da-fundacao-museu-datecnologia-de-sao-paulo-capitulo-i-da-denominacao-regime-juridico-duracao-sede-eforo.html>. Acesso em: 13 jun. 2017.

GASPAR. A. Museus de ciência: conceituação e proposta de um referencial teórico. 1993 118 f. Tese (Doutorado em Didática) - Faculdade de Educação, Universidade de São Paulo, São Paulo, 1993.

GRILLO, S. V. C. Enunciados verbo-visuais na divulgação científica. Revista da Anpoll, Belo Horizonte, n. 27, p. 215-246, jan./jun. 2009.

. Divulgação científica: linguagens, esferas e gêneros. 2013. 333 f. Tese (Livredocência em Filologia e Língua Portuguesa) - Universidade de São Paulo, São Paulo, 2013.

MEDVIÉDEV, P. N. O método formal nos estudos literários. Introdução crítica a uma poética sociológica. Tradução de Sheila V. C. Grillo e Ekaterina V. Américo. São Paulo: Contexto, 2012 [1928].

SABBATINI, M. Museus e centros de ciências virtuales: complemetación y potenciación del aprendizaje de ciências através del expriementos virtuales. 2004. 599 f. Tese (Doutorado em Teoria e História da Educação) - Universidade de Salamanca, Salamanca, 2004.

SILVA, G.; AROUCA, M.; QUIMARÃES, V. As exposições de divulgação científica. In: MASSARANI, L.; MOREIRA, I. C.; BRITO, F. (Org.). Ciência e público, caminhos da divulgação científica no Brasil. Rio de Janeiro: Casa da Ciência - Centro Cultural de Ciência e tecnologia da Universidade Federal do Rio de Janeiro, 2002.

TIBÚRCIO. B. M. C. Instrumentos cientificos, um desafio para os museus: estudo de caso das comissões de Luiz Cruls ao Planalto Central do Brasil. 2013. 167 f. Dissertação de Mestrado apresentada à Coordenação do Programa de Pós-Graduação em Museologia e Patrimônio. Universidade Federal do Estado do Rio de Janeiro, RJ. 
TUNDISI, J. G. Programa nacional de popularização da ciência. In: CRESTANA. M; PEREIRA. S.; CASTRO, M. G.; PEREIRA, GILSON, R. de M. (Orgs.). Centros e museus de ciência: visões e experiências: subsídios para um programa nacional de popularização da ciência. São Paulo: Saraiva: Estação Ciência, 1998.

VALENTE, M. E. A. A conquista do caráter público do museu. In: GOUVÊA, G.; MARANDINO, M.; LEAL. M. C. (Org.). Educação e museu: a construção social do caráter educativo dos museus de ciência. Rio de Janeiro: Access, 2003. p. 21-45.

VOGT, C. Ciência, Comunicação e Cultura Científica. In: (Org.). Cultura Cientifica: Desafios. EDUSP: Fapesp, 2006. p. 19-26.

Recebido em: 22/08/2016

Aprovado em: 29/11/2016 